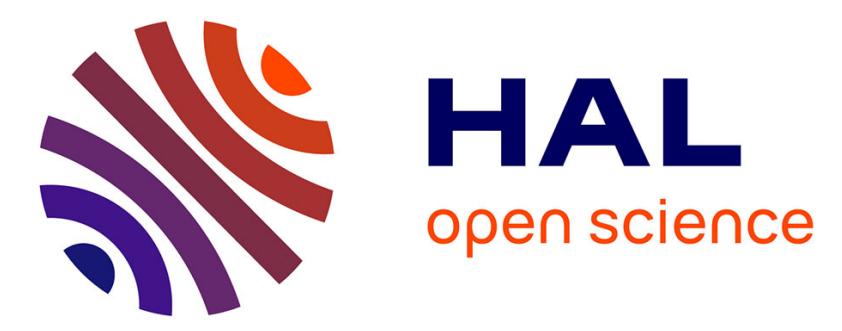

\title{
Complexity Reduction of Ultrasound Sub-Ultra-Harmonic Modeling by an Input Modified Volterra Approach
}

Fatima Sbeity, Sébastien Ménigot, Emma Kanbar, Nesrine Houhat, Jamal Charara, Jean-Marc Girault

\section{To cite this version:}

Fatima Sbeity, Sébastien Ménigot, Emma Kanbar, Nesrine Houhat, Jamal Charara, et al.. Complexity Reduction of Ultrasound Sub-Ultra-Harmonic Modeling by an Input Modified Volterra Approach . IEEE International Ultrasonic Symposium 2017, Sep 2017, Washington, United States. 10.1109/ULTSYM.2017.8092060 . hal-01586788

\section{HAL Id: hal-01586788 \\ https://hal.science/hal-01586788}

Submitted on 14 Sep 2017

HAL is a multi-disciplinary open access archive for the deposit and dissemination of scientific research documents, whether they are published or not. The documents may come from teaching and research institutions in France or abroad, or from public or private research centers.
L'archive ouverte pluridisciplinaire HAL, est destinée au dépôt et à la diffusion de documents scientifiques de niveau recherche, publiés ou non, émanant des établissements d'enseignement et de recherche français ou étrangers, des laboratoires publics ou privés. 


\title{
Complexity Reduction of Ultrasound Sub-Ultra-Harmonic Modeling by an Input Modified Volterra Approach
}

\author{
Fatima Sbeity ${ }^{*}$, Sébastien Ménigot ${ }^{\dagger \ddagger}$, Emma Kanbar ${ }^{\dagger}$, Nesrine Houhat ${ }^{\S}$, Jamal Charara ${ }^{*}$ and Jean-Marc Girault ${ }^{\dagger \ddagger}$ \\ * Department of Physics and Electronics, Faculty of Sciences I, Lebanese University, Beirut, Lebanon \\ ${ }^{\dagger}$ Université François-Rabelais de Tours, Inserm, Imagerie et Cerveau UMR U930, Tours, France \\ * Université François-Rabelais de Tours, CNRS, CEA, INSA-CVL, GREMAN UMR7347, Tours, France \\ ${ }^{\S}$ Research Center in Industrial Technologies CRTI ex-CSC, Algiers, Algeria \\ Email: fatima.sbeity@ul.edu.lb, sebastein.menigot@univ-tours.fr, emma.kanbar@etu.univ-tours.fr,n.houhat@crti.dz, \\ jcharara@ul.edu.lb, jean-marc.girault@univ-tours.fr
}

\begin{abstract}
Contrast of echographic images has been highly improved by the injection of microbubbles, due to their nonlinear behavior. However, this contrast enhancement is limited by the nonlinear acoustic propagation in tissue. To overcome this drawback, sub and ultra-harmonic contrast imaging can be used, since only microbubbles can generate these components. Nonlinear modeling is a primordial step in the analysis of microbubble signals for sub and ultra-harmonic imaging. Nonlinear models like Volterra model has been applied in harmonic imaging to model harmonics optimally. However, it can model harmonics only. For sub and ultra-harmonic modeling, a multiple input single output (MISO) Volterra has been proposed. The aim of this study is to propose a simpler alternative for the modeling of sub and ultra-harmonics. We propose a modified single input single output (SMISO) Volterra model based on input demodulation. The model is tested using simulated and experimental signals. Results showed that sub and ultra-harmonics are modeled. The number of kernels is reduced to its half using SMISO model compared to MISO model. The relative mean square error between the simulated signal and the modeled signal with SMISO Volterra model is $-15.8 \mathrm{~dB}$ and it is $-60.7 \mathrm{~dB}$ for experimental signals. The computational time is reduced by a factor of 4 and 5 in simulated and experimental cases respectively. SMISO model can make easier the sub and ultra-harmonics modeling.
\end{abstract}

Keywords—modeling, sub-ultra-harmonics, SMISO Volterra, demodulation, microbubble.

\section{INTRODUCTION}

Contrast of ultrasound images has been highly improved with the introduction of ultrasound contrast agents consisted of gas microbubbles [1]. This contrast enhancement is mainly due to the non-linear acoustic oscillation of microbubbles [2]. Traditionally, contrast ultrasound imaging consists in transmitting at the frequency fo and receiving at the second harmonic $2 \mathrm{f}_{0}[3]$, [4]. This modality is known as second harmonic imaging. Harmonic extraction could be carried out by using non-linear models, such as Volterra model [5]. These

methods, that use a single input and output (SISO) Volterra model allowed to increase the CTR with respect to the linear bandpass filtering centered around $2 \mathrm{f}_{0}[5]$.

However, the contrast in second harmonic imaging is limited by the presence of second harmonic in the echo of the surrounding tissue [6]. To overcome this limitation, sub and ultraharmonic imaging can be used. They consist in transmitting at the frequency $\mathrm{f}_{0}$ and receiving at the subharmonic $\mathrm{f}_{0} / 2$ [7] and ultra-harmonic frequencies $\left(3 / 2 \mathrm{f}_{0}, 5 / 2 \mathrm{f}_{0}, \ldots\right)$ [8] respectively, which are generated exclusively by microbubbles [9] with particular acoustic [7] and physical conditions [10]. Note that, in our work, we deal with conventional settings of imaging pressure levels. If the pressure level is very strong, as in high intensity focused ultrasound (HIFU) exposures, then subharmonic imaging can be performed by cavitation [11].

SISO Volterra model cannot be used directly in sub and ultra-harmonics imaging, since it models harmonics only [12]. Exciting methods for modeling sub and ultra-harmonics (SUH) use a multiple input single output (MISO) Volterra model [13], [14], [15], [16]. The main drawback of MISO Volterra methods is the large number of kernels to be evaluated, which leads to a high computational cost. However, other proposed solutions are based on the use of Hammerstein model [17], [18]; they allow the extraction of sub and ultra-harmonic components. Unfortunately, it is only possible by restraining the assumptions on the model.

In this paper, we are interested in the reduction of complexity of sub and ultra-harmonic modeling based on the use of Volterra model with modified input. Note that the algorithm complexity lies in an inversion matrix in $\mathrm{O}\left(\mathrm{n}^{3}\right)$ by using the Gauss-Jordan elimination. Simplifying the model is thus crucial for experimental application of such technique. Therefore, the proposed solution is based on a modified single input single output (SMISO) Volterra structure applied on simulated and experimental microbubbles signals. 


\section{SUB AND ULTRA-HARMONIC MODELING}

Standard SISO Volterra model can be considered as a Taylor expansion with memory [19]. Due to its polynomial formalism, it can only model harmonic components generated by a nonlinear system. In order to model SUH, one way is to modify the input signal in such away to have the subharmonic frequency $\mathrm{f}_{0} / 2$ at the input of the model. Therefore, sub and ultra-harmonics can be modeled as they can be seen by the model as integer multiples of the input frequencies.

\section{A. SISO and MISO Volterra model}

For a nonlinear system with input $\mathrm{x}(\mathrm{n})$ and output $\mathrm{y}(\mathrm{n})$, in discrete time $\mathrm{n}$, the standard SISO Volterra model, of order $\mathrm{P}$ and truncated to a memory $\mathrm{M}$ is given by the following equation:

$$
\begin{aligned}
& \hat{\mathrm{y}}(\mathrm{n})=\mathrm{h}_{0}+\sum_{\mathrm{k}_{1}=0}^{\mathrm{M}-1} \mathrm{~h}_{1}\left(\mathrm{k}_{1}\right) \mathrm{x}\left(\mathrm{n}-\mathrm{k}_{1}\right) \\
& +\sum_{\mathrm{k}_{1}=0}^{\mathrm{M}-1} \mathrm{~h}_{2}\left(\mathrm{k}_{1}, \mathrm{k}_{2}\right) \mathrm{x}\left(\mathrm{n}-\mathrm{k}_{1}\right) \mathrm{x}\left(\mathrm{n}-\mathrm{k}_{2}\right) \\
& +\ldots \\
& +\sum_{\mathrm{k}_{1}=0}^{\mathrm{M}-1} \ldots \sum_{\mathrm{k}_{\mathrm{P}}=0}^{\mathrm{M}-1} \mathrm{~h}_{\mathrm{P}}\left(\mathrm{k}_{1}, \ldots, \mathrm{k}_{\mathrm{P}}\right) \mathrm{x}\left(\mathrm{n}-\mathrm{k}_{1}\right) \ldots \mathrm{x}\left(\mathrm{n}-\mathrm{k}_{\mathrm{P}}\right)
\end{aligned}
$$

Where $h_{p}\left(k_{1}, k_{2}, \ldots, k_{p}\right)$ is the kernel of order $p$ with $p \in\{1,2, \ldots, P\}$

The total number of kernels increases drastically with $\mathrm{P}$ and $\mathrm{M}$. A simplification can be obtained by considering the symmetry of the kernels. Symmetry means that $h_{p}\left(k_{1}, k_{2}, \ldots, k_{p}\right)$ are invariant if the order of the indexes $k_{i}, i \in\{1,2, \ldots, p\}$ is exchanged [20]. By considering this symmetry, the total number $\mathrm{N}_{\mathrm{Psym}}$ of kernels is given by the following equation:

$$
\mathrm{N}_{\mathrm{P}_{\mathrm{sym}}}=\sum_{\mathrm{p}=1}^{\mathrm{P}} \mathrm{C}_{\mathrm{P}}^{\mathrm{M}+\mathrm{p}-1}=\sum_{\mathrm{p}=1}^{\mathrm{P}} \frac{(\mathrm{M}+\mathrm{p}-1) !}{(\mathrm{M}-1) ! \mathrm{p} !}
$$

For SUH modeling using MISO Volterra model, the input signal is decomposed to $\mathrm{N}_{\text {sub }}$ orthogonal inputs, where $\mathrm{N}_{\text {sub }}$ is the order of the subharmonic frequency. Each input signal is of frequency $\mathrm{f}_{0} / \mathrm{N}_{\text {sub }}$. Therefore, the model can be viewed as a succession of $\mathrm{N}_{\text {sub }}$ SISO Volterra models. As a result, the number of kernels to be evaluated for a MISO model is $\mathrm{N}_{\text {sub }}$ times that for a SMISO model: $\mathrm{N}_{\text {sub }} \times \mathrm{N}_{\text {Psym }}$. Note that the standard algorithm complexity is consequently in $\mathrm{O}\left(\mathrm{n}^{3}\right)$ with $\mathrm{n}$ proportional to $\mathrm{N}_{\text {sub }} \times \mathrm{N}_{\mathrm{Psym}}$.

To reduce the number of kernels, we propose here a SMISO Volterra model. The basic idea is to modify the frequency of the input signal without decomposition to preserve a single input Volterra structure.

\section{B. SMISO Volterra model}

The SMISO model that we proposed here is based on the same concept as the MISO model. The input signal is demodulated by $f_{0} / \mathrm{N}_{\text {sub }}$, to include the subharmonic frequency. In the case of microbubble signals $\mathrm{N}_{\text {sub }}=2$. The new modified input $\mathrm{z}(\mathrm{n})$ of the SMISO model is obtained by adding the demodulated input $\mathrm{x}_{\bmod }(\mathrm{n})$ of frequency $\mathrm{f}_{0} / 2$ and the input $\mathrm{x}(\mathrm{n})$ of frequency fo following the equation:

$$
z(n)=x(n)+x_{\text {mod }}(n)=x(n)+R\left(x_{a}(n) \cdot e^{-2 \pi j \frac{f_{0}}{2} n T_{s}}\right),
$$

where $R$ represents the real part, $x_{a}(n)$ is the analytic signal of $x(n)$, and $T_{s}=1 / f_{s}$ is the sampling period, with $f_{s}$ is the sampling frequency.

A SMISO Volterra model of input $\mathrm{z}(\mathrm{n})$, illustrated in Fig. 1, is able to model SUH as they can be considered as linear combinations and integer multiples of the inputs frequencies. The modeling process is resumed to finding the kernels $\mathrm{h}_{\mathrm{p}}\left(\mathrm{k}_{1}, \mathrm{k}_{2}, \ldots, \mathrm{k}_{\mathrm{p}}\right)$ of the SMISO model.

Equation (1), with input $\mathrm{z}(\mathrm{n})$, could be rewritten, with an algebric formula, as follows:

$$
\mathrm{Y}=\mathrm{Z} \cdot \mathrm{H}
$$


Where $\mathrm{Y}$ is the output signal:

$$
\mathrm{Y}=[\mathrm{y}(\mathrm{M}+1), \mathrm{y}(\mathrm{M}+2), \ldots, \mathrm{y}(\mathrm{L})]^{\mathrm{T}} \text {, }
$$

With $\mathrm{L}$ is the length of the signal, $\mathrm{H}$ is the vector of kernels:

$$
\begin{aligned}
& \mathrm{H}=\left[\mathrm{h}_{1}(0), \ldots, \mathrm{h}_{1}(\mathrm{M}-1), \mathrm{h}_{2}(0,0), \ldots, \mathrm{h}_{2}(\mathrm{M}-1, \mathrm{M}-1),\right. \\
& \left.\ldots, \mathrm{h}_{\mathrm{P}}(0,0, \ldots 0), \ldots, \mathrm{h}_{\mathrm{P}}(\mathrm{M}-1, \mathrm{M}-1, \ldots, \mathrm{M}-1)\right]^{\mathrm{T}},
\end{aligned}
$$

and where $\mathrm{Z}$ is the input matrix:

$$
\mathrm{Z}=\left[\mathrm{z}_{\mathrm{M}+1}, \mathrm{z}_{\mathrm{M}+2}, \ldots, \mathrm{z}_{\mathrm{L}}\right]^{\mathrm{T}} \text {, }
$$

with the vector:

$$
\begin{aligned}
& z_{n}=\left[z(n), \ldots, z\left(n-M+1, z^{2}(n), z(n) z(n-1),\right.\right. \\
& \left.\ldots, z^{2}(n-M+1), z(n) z(n) z(n-1), \ldots, z^{3}(n-M+1)\right]^{T},
\end{aligned}
$$

with $1 \in\{\mathrm{M}-1, \mathrm{M}, \ldots, \mathrm{L}\}$.

The vector of kernels $\mathrm{H}$ is calculated to minimize the error between the output signal $\mathrm{y}(\mathrm{n})$ and the modeled signal $\hat{\mathrm{y}}(\mathrm{n})$. The vector $\mathrm{H}$ can be obtained with a pseudo-inversion solution, such as:

$$
\mathrm{H}=\left(\mathrm{Z}^{\mathrm{T}} \mathrm{Z}\right)^{-1} \mathrm{Z}^{\mathrm{T}} \mathrm{Y} \text {. }
$$

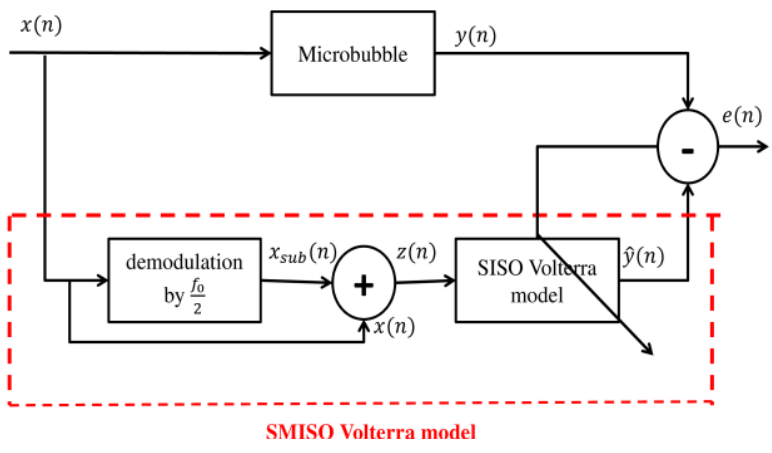

Fig. 1. Blockdiagram of a SMISO Volterra model.

Note that the new algorithm complexity remains in $\mathrm{O}\left(\mathrm{n}^{3}\right)$, but where $\mathrm{n}$ is proportional to $\mathrm{N}_{\text {Psym }}$.

SMISO Volterra model is applied on simulated and experimental microbubble signals. Modeling is performed with Matlab® (Mathworks, Natick, MA, USA) using a CPU: 2 processors Xeon E5-2630 with a clock at $2.3 \mathrm{GHz}$ and 48 Go Ram.

\section{SIMULATION SETUP AND SIMULATION RESULTS}

The oscillation of microbubbles is simulated using a free simulation program Bubblesim developed by Hoff [21]. The incident burst to the microbubble is a sinusoidal wave of frequency $\mathrm{f}_{0}=4 \mathrm{MHz}$, at $1.6 \mathrm{MPa}$ pressure, and consists of 32 cycles. Under these conditions, the oscillation of the microbubble presents SUH. The sampling frequency is $\mathrm{f}_{\mathrm{s}}=60 \mathrm{MHz}$ [7]. The parameters of the microbubble are given in the table I [21].

Fig. 2 shows, the excitation signal and the modified input, for SMISO model in time and frequency domains. The spectrum of the modified input shows clearly that it has both the fundamental and sub-harmonic frequencies.

Fig. 3 shows the time and frequency domain representations of the microbubble signal and those modeled with MISO and MISO Volterra models. Time domain representations show that the modeled signal with SMISO model follows well the microbubble signal. The spectra of the modeled signals are identical to that of the microbubble signal. Therefore, the SMISO model can model SUH generated by the microbubble in addition the harmonics.

Quantitatively, the effectiveness of SMISO Volterra model with respect the MISO Volterra model is evaluated in terms of the relative mean square error (rMSE) between the modeled signal with each model and the output of microbubble, the number of kernels, and the computation time. Results reported in table II show that both models provides approximately the same rMSE, the 
number of kernels is reduced to its half by using SMISO model, and the computational time is reduced by a factor of 4 with SMISO model.

\section{EXPERIMENTAL SETUP AND EXPERIMENTAL RESULTS}

Experiments are carried out by using the same experimental used in [17]. The excitation signal is transmitted to a $10 \mathrm{MHz}$ PZT single element. Responses of a diluted solution of Sonovue ${ }^{\mathrm{TM}}$ microbubbles were measured by a $5 \mathrm{MHz}$ PZT single element transducer. Measured echoes were amplified by $30 \mathrm{~dB}$, visualized on a digital oscilloscope then transferred to a personal computer.

TABLE I. THE PARAMETERS OF MICROBUBBLES [21].

\begin{tabular}{|c|c|}
\hline Resting radius & $\mathrm{R}_{0}=2 \mu \mathrm{m}$ \\
\hline Shell thickness & $\mathrm{d}_{\mathrm{Se}}=4 \mathrm{~nm}$ \\
\hline Shear modulus & $\mathrm{G}_{\mathrm{s}}=50 \mathrm{MPa}$ \\
\hline shear viscosity & $\eta=0.8 \mathrm{~Pa} . \mathrm{s}$ \\
\hline
\end{tabular}
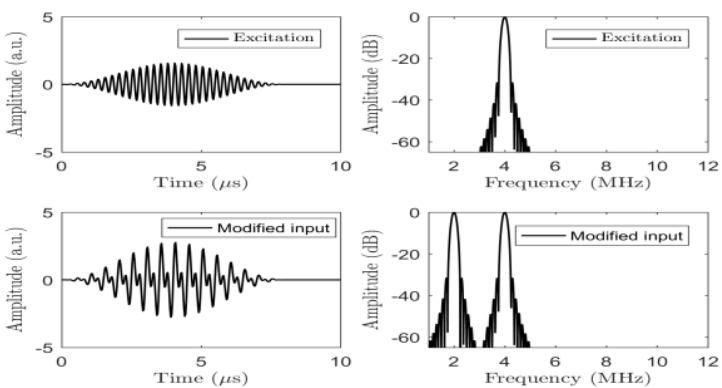

Fig. 2. Excitation signal $x(n)$ at the top and modified input signal $z(n)$ at the bottom, in the simulated case.

Figs. 4 and 5 show identical results as those shown in Figs. 2 and 3 for the experimental case.

For experimental signals, in order to model the signal on the full duration, here $10 \mu \mathrm{s}$, the memory $\mathrm{M}$ of Volterra model had to be equal to the samples number, as here 5000 and the order is equal to $\mathrm{P}=1$ since the output signal has only subharmonic and fundamental frequencies. Normally, a Volterra model of order $\mathrm{P}=1$ can only model the fundamental frequency. Since for SMISO Volterra model, the modified input has both sub-harmonic and fundamental frequencies, they are considered as a fundamental frequency for the SMISO Volterra model and then they can be modeled.

Quantitative comparison is presented in Table III. Results show that the rMSE is reduced by a factor of $8.5 \mathrm{~dB}$ with SIMSO Volterra model; this is due to the high memory of the model. The number of kernels is reduced to its half by using SMISO Volterra model.
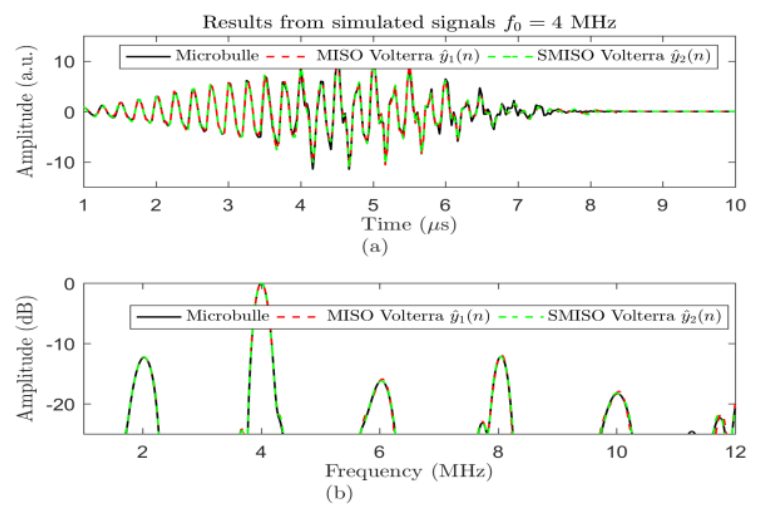

Fig. 3. (a) simulated microbubble signal (black), modeled signal with MISO model (red) and SMISO model (green). (b) spectra for the signals in (a). $\mathrm{P}=3$ and $\mathrm{M}=35$. 
TABLE II. QUANTATIVE COMPARISON BETWEEN MISO VOLTERRA MODEL AND SMISO VOLTERRA MODEL FOR SIMULATED SIGNALS.

\begin{tabular}{|c|c|c|c|}
\hline Model & MISO & SMISO & Ratio(MISO/SMISO) \\
\hline rMSE (dB) & -15.5 & -15.8 & 1.02 \\
\hline $\begin{array}{c}\text { Computation } \\
\text { time (s) }\end{array}$ & 960.14 & 236.5 & 4 \\
\hline $\begin{array}{c}\text { Number of } \\
\text { kernels }\end{array}$ & 16870 & 8435 & 2 \\
\hline
\end{tabular}
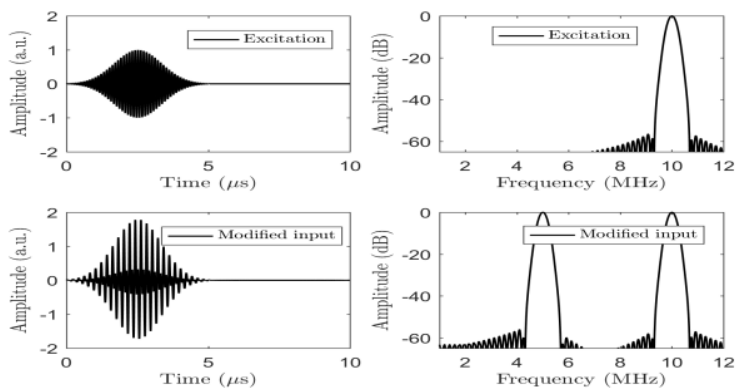

Fig. 4. Excitation signal $x(n)$ at the top and modified input signal $z(n)$ at the bottom, in the experimental case.

\section{DISCUSSIONS AND CONCLUSION}

SMISO Volterra model allows an optimal modeling of microbubble signals that present sub and ultra-harmonics. Required prior knowledge includes only the center frequency of the excitation set by the user, and the frequency range in the output usually defined by the transducer. The importance of MISO Volterra model lies in the significant reduction of the computation time with a significant gain in terms of rMSE for experimental signals due to the intermodulation present in the modified input signal.

To conclude, SMISO Volterra model can be considered as a simple, quick and efficient method to model sub and ultraharmonics.
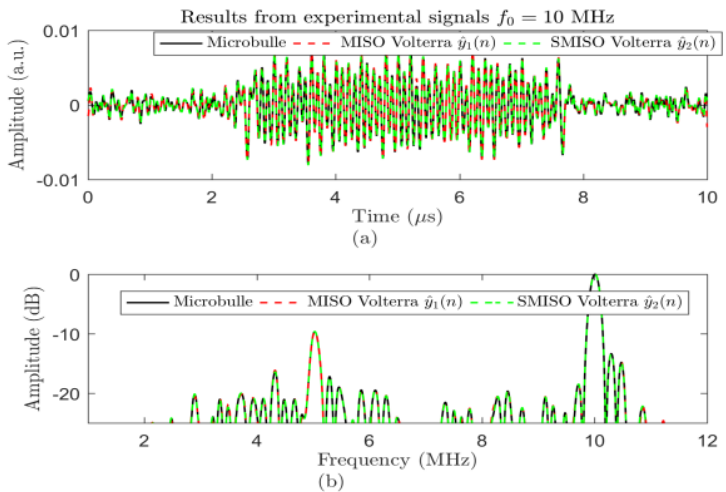

Fig. 5. (a) experimental microbubble signal (black), modeled signal with MISO model (red) and SMISO model (green). (b) spectra for the signals in (a). $\mathrm{P}=1$ and $\mathrm{M}=5000$.

TABLE III. QUANTATIVE COMPARISON BETWEEN MISO VOLTERRA MODEL AND SMISO VOLTERRA MODEL FOR EXPERIMENTAL SIGNALS.

\begin{tabular}{|c|c|c|c|}
\hline Model & MISO & SMISO & Ratio(MISO/SMISO) \\
\hline rMSE (dB) & -17.5 & -63.7 & 8.5 \\
\hline $\begin{array}{c}\text { Computation } \\
\text { time (s) }\end{array}$ & 236.5 & 48.5 & 5 \\
\hline $\begin{array}{c}\text { Number of } \\
\text { kernels }\end{array}$ & 10000 & 5000 & 2 \\
\hline
\end{tabular}




\section{REFERENCES}

[1] B. B. Goldberg, J.-B. Liu, and F. Forsberg, “Ultrasound contrast agents: A review," Ultrasound in Medicine and Biology, vol. 20, no. 4, pp. 319-333, 1994.

[2] N. de Jong, A. Bouakaz, and P. Frinking, "Harmonic imaging for ultrasound contrast agents," in Proceeding IEEE Ultrasonic Symposium, San Juan, Puerto Rico, Oct. 2000, pp. 1869-1876.

[3] P. N. Burns, "Instrumentation for contrast echocardiography." Echocardiography-A Journal Of Cardiovascular Ultrasound And Allied Techniques, vol. 19, no. 3, pp. 241-258, April 2002.

[4] B. Schrope and V. Newhouse, "Second harmonic ultrasonic blood perfusion measurement," Ultrasound in Medicine and Biology, vol. 19, no. 7, pp. 567 $-579,1993$.

[5] P. Phukpattaranont and E. Ebbini, "Post-beamforming second-order Volterra filter for pulse-echo ultrasonic imaging," IEEE Transactions on Ultrasonics, Ferroelectrics and Frequency Control,, vol. 50, no. 8, pp. 987-1001, 2003.

[6] M. A. Averkiou, "Tissue harmonic imaging," in Proc IEEE Ultrason Symp, vol. 2, 2000, pp. 1563 -1572.

[7] F. Forsberg, W. T. Shi, and B. B. Goldberg, "Subharmonic imaging of contrast agents," Ultrasonics, vol. 38, pp. 93-98, 2000.

[8] R. Basude and M. Wheatley, "Generation of ultraharmonics in surfactant based ultrasound contrast agents: Use and advantages." Ultrasonics, vol. 39, pp. 437-444, 2001.

[9] P. M. Shankar, P. D. Krishna, and V. L. Newhouse, "Advantages of subharmonic over second harmonic backscatter for contrast-to-tissue echo enhancement," Ultrasound Med Biol, vol. 24, no. 3, pp. 395 - 399, Mar. 1998.

[10] E. Kanbar, D. Fouan, C. A. Sennoga, and A. Bouakaz, "Impact of gas composition on subharmonic emission from phospholipid contrast agents," in The European symposium on Ultrasound Contrast Imaging, Rotterdam, The Netherlands, Jan. 2016.

[11] C. Bai, S. Xu, J. Duan, B. Jing, M. Yang, and M. Wan, "Pulse-inversion subharmonic ultrafast active cavitation imaging in tissue using fast eigenspacebased adaptive beamforming and cavitation deconvolution," IEEE Transactions on Ultrasonics, Ferroelectrics, and Frequency Control, vol. 64, no. 8, pp. 1175 -1193, Aug 2017.

[12] S. Boyd, L. O. Chua, and C. A. Desoer, "Analytical foundations of Volterra series," IMA Journal of Mathematical Control \& Information, vol. 1, pp. 243282, 1984.

[13] O. Boaghe and S. Billings, "Subharmonic oscillation modeling and MISO Volterra eeries," IEEE Transactions On Circuits And Systems, vol. 50, no. 7, pp. $877-884$, July 2003.

[14] C. Samakee and P. Phukpattaranont, "Application of MISO Volterra Series for modeling subharmonic of ultrasound contrast agent.” International Journal of Computer and Electrical Engineering, vol. 4, no. 4, pp. 445 - 451, August 2012.

[15] C. Samakee and P. Phukpattaranont, "Efficient MISO 3rd-order Volterra series for modeling sub-harmonic oscillation of ultrasound contrast agent." in IEEE EMBS Conference on Biomedical Engineering and Sciences (IECBES), 2012, 2012, pp. 901- 906.

[16] F. Sbeity, S. Ménigot, J. Charara, and J.-M. Girault, "A General Framework for modeling sub and ultra-harmonics of ultrasound contrast agent signals with MISO Volterra series." Computational and Mathematical Methods in Medecine, 2013.

[17] F. Sbeity, S. Ménigot, J. Charara, and J.-M. Girault, "Contrast improvement in sub- and ultraharmonic ultrasound contrast imaging by combining several Hammerstein models," International Journal of Biomedical Imaging, vol. 2013, p. 9, Sep. 2013.

[18] S. Ménigot, E. Kanbar, A. Bouakaz, and J.-M. Girault, "SNR improvement by subharmonic extraction with Hammerstein models for microbubble signals," in 2016 IEEE International Ultrasonics Symposium (IUS), Sept 2016, pp. 1- 4.

[19] V. Volterra, Theory of functionals and of integral and integro-differential equations. Glasgow, UK: Blackie \& Son, 1930.

[20] M. Schetzen, The Volterra and Wiener theories of nonlinear systems. New York, NY, USA: Wiley, 1980.

[21] L. Hoff, Acoustic Characterization of Contrast Agents for Medical Ultrasound Imaging. Boston, USA: Kluwer Academic, 2001. 